\title{
Thermal Studies of Non-Circular Journal Bearing Profiles: Offset-Halves and Elliptical
}

\author{
Amit Chauhan and Rakesh Sehgal \\ Additional information is available at the end of the chapter
}

http://dx.doi.org/10.5772/51261

\section{Introduction}

Hydrodynamic journal bearings are defined as the mechanical components that support the external loads smoothly due to geometry and relative motion of mating surfaces in the presence of a thick film of lubricant. Hydrodynamic journal bearings are extensively used in high speed rotating machines because of their low friction, high load capacity, and good damping characteristics. Such bearings have many different designs to compensate for differing load requirements, machine speeds, cost, and dynamic properties. One unique disadvantage which consumes much time towards the research and experimentation is an instability which manifests itself as oil whip which is a vibration phenomenon. Oil whip is disastrous because the rotor cannot form a stable wedge and consequently this leads to metal to metal contact between the rotor and the bearing surface. Once surface contact exists the rotors begins to precess, in a reverse direction from the actual rotor rotation direction, using the entire bearing clearance. This condition leads to high friction levels which will overheat the bearing metal thus causing rapid destruction of the bearing, rotor journal and machine seals. Fuller [1956] has suggested that the fluid film bearings are probably the most important mechanical components in the recent technological development and are comparable in their significance to the effect of electricity. The development of fluid film lubrication mechanisms has been observed by Petrov [1883] in Russia and Tower [1883] in England. In 1886, Reynolds presented his classical analysis of bearing hydrodynamics, which forms the basis of present days bearing study. The overview of both the circular and non-circular hydrodynamic journal bearings and their design methodologies are discussed as follows:

\subsection{Circular journal bearing}

The basic configuration of the circular journal bearing consists of a journal which rotates relative to the bearing which is also known as bush (Fig. 1). Efficient operation of such 
bearing requires the presence of a lubricant in the clearance space between the journal and the bush. In hydrodynamic lubrication it is assumed that the fluid does not slip at the interface with the bearing and journal surface i.e. the fluid in contact with the journal surface moves at the same speed as the journal surface. Over the thickness of the fluid there is a velocity gradient depending on the relative movement of the bearing surfaces. If the bearing surfaces are parallel or concentric, the motion of the lubricant will not result in pressure generation which could support bearing load.

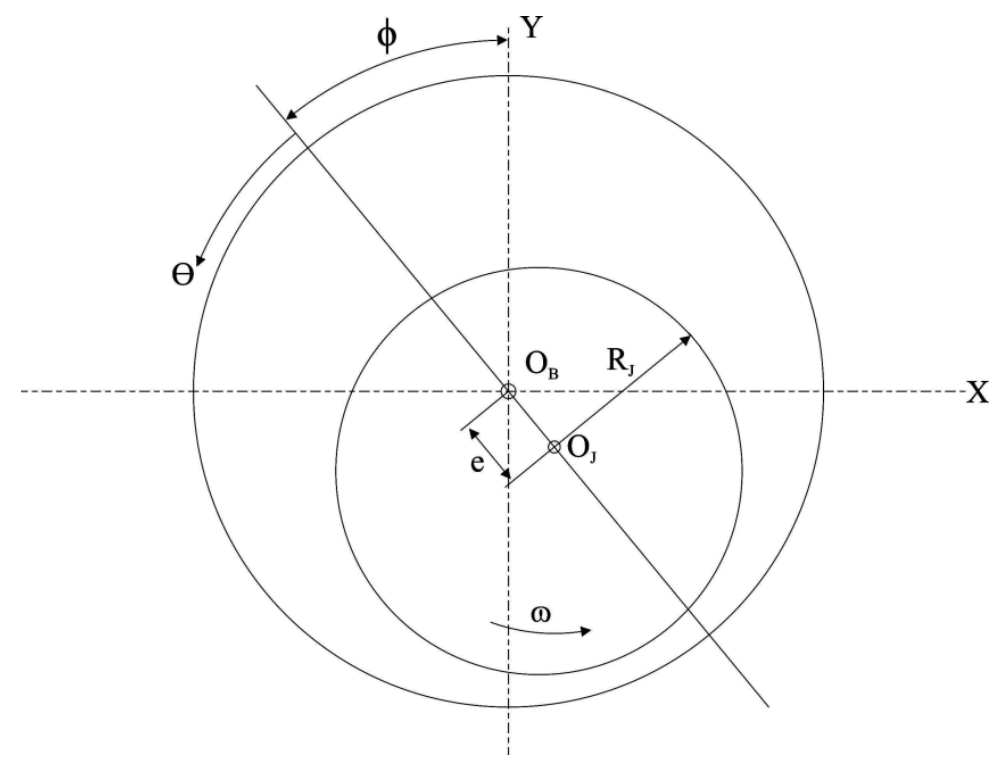

Figure 1. Schematic of circular journal bearing

However, if the surfaces are at a slight angle, the resulting lubrication fluid velocity gradients will be such that generation of pressure results from the wedging action of the bearing surfaces. Hydrodynamic lubrication depends upon this effect. The operation of hydrodynamic lubrication in journal bearings has been illustrated in Fig. 2. Before the rotation commences i.e. at rest the shaft rests on the bearing surface. When the journal starts to rotate, it will climb the bearing surface gradually as the speed is further increased; it will then force the lubricant into the wedge-shaped region. When more and more lubricant is forced into a wedge-shaped clearance space, the shaft moves up the bore until an equilibrium condition is reached and now, the shaft is supported on a wedge of lubricant. The moving surfaces are then held apart by the pressure generated within the fluid film. Journal bearings are designed such that at normal operating conditions the continuously generated fluid pressure supports the load with no contact between the bearing surfaces. This operating condition is known as thick film or fluid film lubrication and results in a very low operating friction. On the other hand if the lubricant film is insufficient between the relatively moving parts, it may lead to surface contact and the phenomenon is normally known as boundary lubrication. This occurs at rotation start-up, a 
slow speed operation or if the load is too heavy. This regime results in bearing wear and a relatively high friction value. If a bearing is to be operated under boundary lubricating conditions, special lubricants must be used. Amongst hydrodynamic bearings, circular journal bearing is the most familiar and widely used bearing. Simple form of this bearing offers many advantages in its manufacturing as well as in its performance. However, the circular journal bearings operating at high speed encounter instability problems of whirl and whip. Instability may damage not only the bearings but also the complete machine.
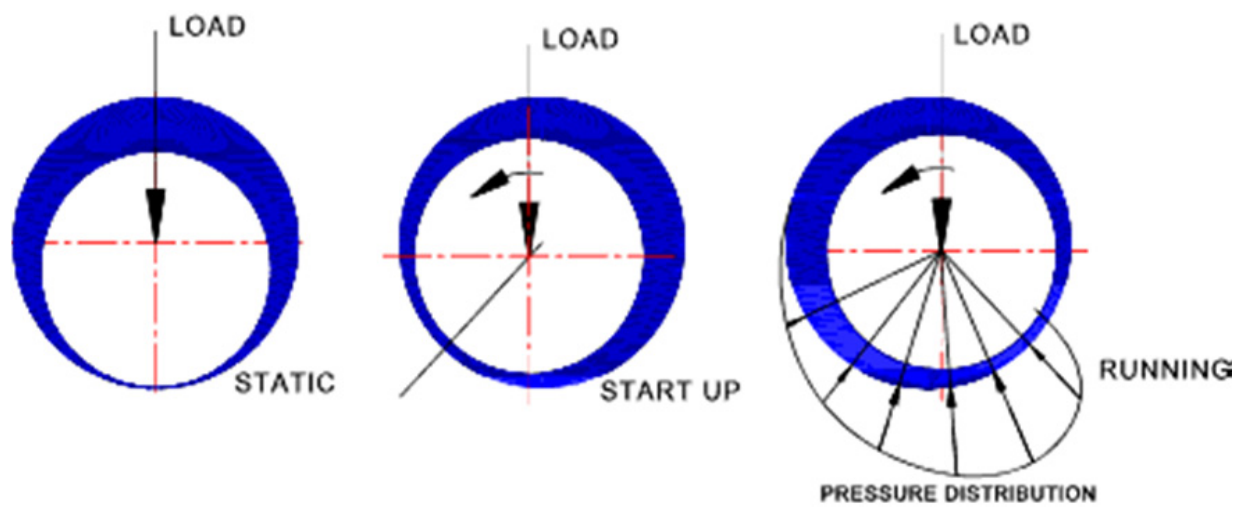

Figure 2. Schematic of operation of hydrodynamic lubrication in journal bearing [W1]

Moreover, these bearings usually experience a considerable variation in temperature due to viscous heat dissipation. This significantly affects the bearing performance as lubricant viscosity is a strong function of temperature. Furthermore, excessive rise in temperature can cause oxidation of the lubricant and, consequently, lead to failure of the bearing. Pressure also influences the viscosity of the lubricant to certain extent. Usually viscosity increases exponentially as the pressure increases which in turn increases the load capacity of the journal bearing. Researchers have studied the behaviour of circular journal bearing by adopting various numerical approaches to simulate the performance in accordance with the real conditions.

\subsection{Non-circular journal bearing}

It has been reported in the literature that the temperature rise is quite high in circular journal bearings as they operate with single active oil film. This resulted in the development of bearings with non-circular profile which operate with more than one active oil film. This feature accounts for the superior stiffness, damping, and reduced temperature in the oil film as compared to the circular journal bearings. Almost all the noncircular journal bearing geometries enhance the shaft stability and under proper conditions this will also reduce power losses and increase oil flow (as compared to an inscribed circular bearing), thus reducing the oil film temperature. Amongst non-circular journal bearings, offset-halves, elliptical, lemon bore, and three-lobe configurations are the most common. 
The offset-halves journal bearing has been commonly used as a lobed bearing in which two lobes are obtained by orthogonally displacing the two halves of a cylindrical bearing. Offsethalves journal bearings (Fig. 3) are frequently used in gear boxes connecting turbine and generator for the power generation industries. These also find applications where primary directions of force, constant direction of rotation are found or high bearing load capacity, long service life, high stiffness, and damping values are the main characteristics under consideration. If the equipment is operated at full power, these requirements can be met by lemon bore bearings. Lemon bore bearing is a variation on the plain bearing where the bearing clearance is reduced in one direction and this bearing has a lower load carrying capacity than the plain bearings, but is more susceptible to oil whirl at high speeds [W2]. However, equipment must often be operated at lower performance levels, particularly in the times of reduced current needs. It is precisely under these conditions that lemon bore bearings may provide unstable conditions, which may require equipment shut down to avoid damage. Offset-halves journal bearings have the durability equal to lemon bore bearings while these show stiffness and damping properties which permit light loads at high rotational speeds. It also offers the advantage of a long, minimally convergent inlet gap, resulting in high load carrying capacity. At the same time, the externally applied force and the compression resulting from the horizontal displacement of the bearing halves accurately holds the shaft in the lubricant film. This effect produces excellent hydrodynamic characteristics, such as elastic rigidity and damping by the oil film. Thus, the offset-halves journal bearings prove to be technical alternative to conventional lemon bore bearings [Chauhan and Sehgal: 2008].

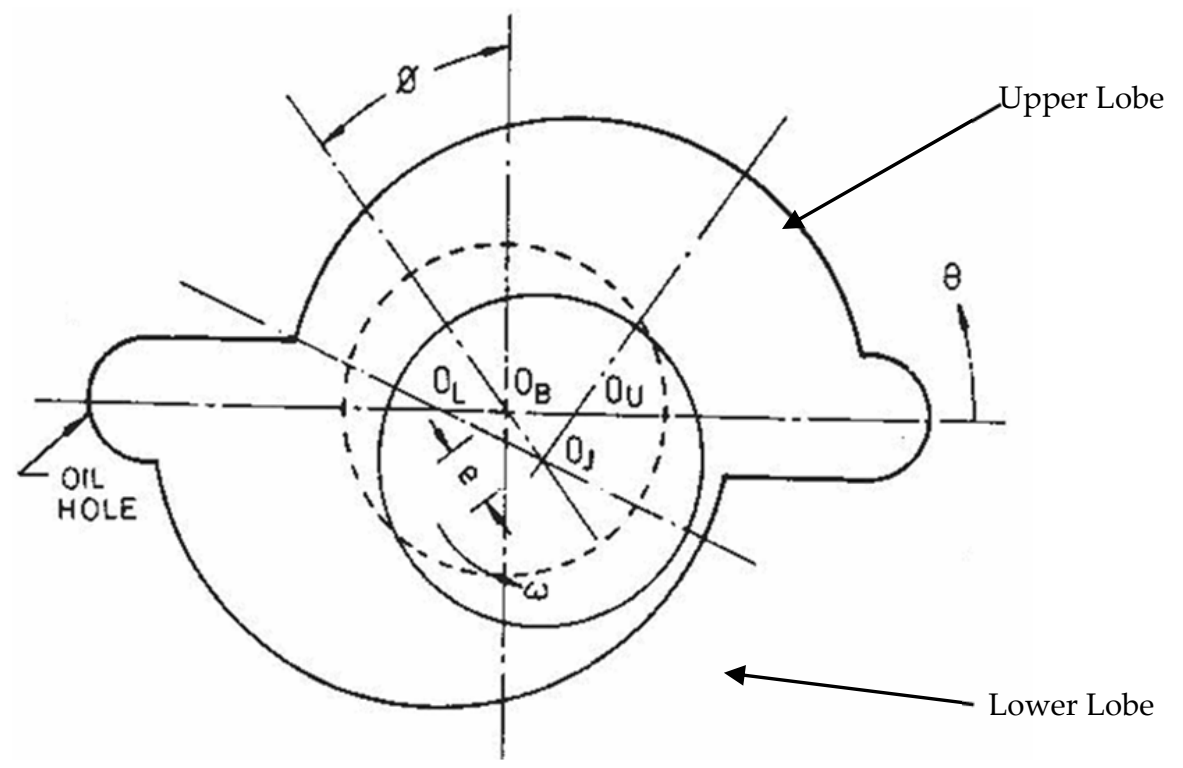

Figure 3. Schematic diagram of offset-halves journal bearing 
The elliptical journal bearings (Fig. 4) are commonly used in turbo-sets of small and medium ratings, steam turbines, and generators. The so-called elliptical journal bearing is actually not elliptic in cross section but is usually made up of two circular arcs whose centers are displaced along a common vertical straight line from the centre of the bearing. The bearing so produced has a large clearance in the horizontal or split direction and a smaller clearance in the vertical direction. Elliptical journal bearings are slightly more stable toward the oil whip than the cylindrical bearings. In addition to this elliptical journal bearing runs cooler than a cylindrical bearing because of the larger horizontal clearance for the same vertical clearance.

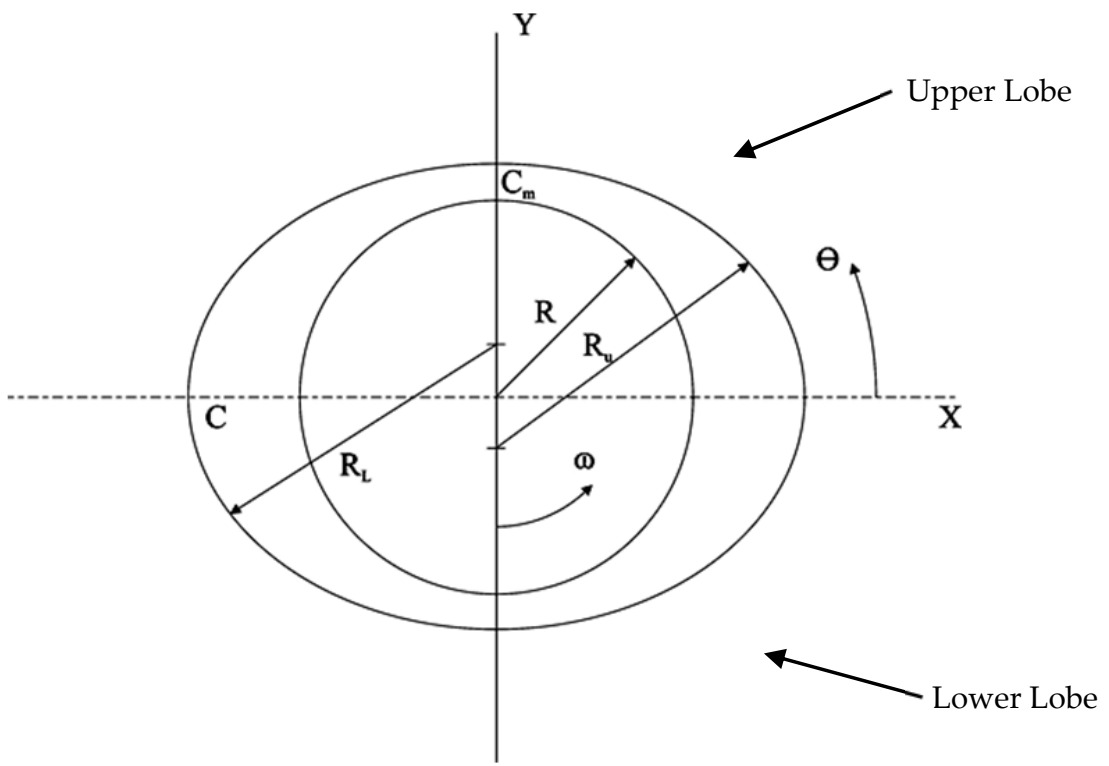

Figure 4. Schematic diagram of elliptical journal bearing

\section{Literature review}

This section of the chapter provides details of research carried out on hydrodynamic bearings in general and, offset-halves and elliptical journal bearings in particular. There is enormous information available on the theoretical and experimental work related to the circular journal bearings. However, such work pertaining to non-circular journal bearings especially offset-halves and elliptical journal bearings are limited and hence, the theoretical and experimental works pertaining to non-circular journal bearings have been summarized:

Pinkus and Lynn [1956] have presented an analysis of elliptical journal bearings based on the numerical solution of Reynolds equation for finite bearings with the assumption that there is no heat loss to the surroundings. They have supplemented the solution of differential equation by additional work on the nature of the oil flow, power loss, and eccentricity in elliptical journal bearings. Wilcock [1961] has worked towards the possibility 
of displacing the lobe centers of two-lobe journal bearings orthogonally with respect to the mid-radius of the lobe. The author shows that when the lobe displacement is in a direction opposite to the shaft surface motion, and the bearing is centrally loaded, shaft stiffness orthogonal to the load vector is substantially increased. At the same time, vertical stiffness essentially remains unchanged and minimum film thickness is decreased; particularly at low loads, while oil flow is increased. Author also carried out an analysis for a bearing having in cross-section two arcs (each subtending an angle of $150^{\circ}$ ), $\mathrm{L} / \mathrm{D}=1 / 2$, and with the arc centers each displaced from the geometric center by half the radial clearance. Singh et al. [1977] have reported that non-circular bearings are finding extensive use in high speed machinery as they enhance shaft stability, reduce power losses and increase oil flow (as compared to circular bearings), thus reducing bearing temperature. The authors had presented a solution to analyze the elliptical bearings, using a variational approach. Crosby [1980] has solved full journal bearing of finite length for thermohydrodynamic case in which the energy transmitted by conduction is included. The effect of temperature variation across the film thickness on bearing performance is investigated by the author. Singh and Gupta [1982] have considered the stability limits of elliptical journal bearings supporting flexible rotors. The Reynolds equation was solved numerically for several values of the eccentricity ratio, the $\mathrm{L} / \mathrm{D}$ ratio and the dimensionless velocity of the journal centre. The authors observed that the operating load, ellipticity, L/D ratio and shaft flexibility significantly affect the limit of stable operation. The authors also reported that elliptical bearings are suitable for stiff and moderately flexible rotors. Tayal et al. [1982] have investigated the effect of nonlinear behavior of additive-fortified lubricants which behave as non-Newtonian fluid on the performance characteristics of the finite width elliptical journal bearing. The finite element method with Galerkin's technique was used to solve the Navier-Stokes equations in cylindrical co-ordinates that represent the flow field in the clearance space of a bearing using Newtonian fluids, and then the non-Newtonian effect was introduced by modifying the viscosity term for the model in the iterations. Booker and Chandra et al. [1983] have compared the performance of different bearing configurations namely offset-halves, lemonbore, three-lobe and four-lobe bearing at the same load capacity and speed. During the comparison, the authors have considered the steady state and stability characteristics. Govindachar [1984] have suggested that Novel 'offset' designs offer attractive possibilities in several applications for which conventional journal bearings are only marginally satisfactory. They considered one such prototypical problem in rotating machinery (the support of a rigid rotor turning at high speed under gravity). The problem has been studied by the authors through a numerical example for both dimensional and non-dimensional parametric studies. The authors show that the stability of full journal bearing system is significantly improved by moderate offset and is fairly insensitive to small departures from optimal design values. Singh and Gupta [1984] have theoretically predicted the stability of a hybrid two-lobe bearing which is obtained by displacing the lobe centers of an elliptical bearing. It has been found that an orthogonally displaced bearing is more stable than the conventional bearings. Mehta and Singh [1986] have analytically analyzed the dynamic behaviour of a cylindrical pressure dam bearing in which centers of both halves are displaced. Authors observed that the stabilities of a cylindrical pressure dam bearing can be 
increased many times by displacing the centers of two halves. It has been reported by the authors that the bearing so obtained is even superior to elliptical and half elliptical pressure dam bearings in stability. Read and Flack [1987] developed a test apparatus on which an offset-halves journal bearing of $70 \mathrm{~mm}$ diameter journal was tested at five vertical loads and two rotational speeds. Singh et al. [1989] have studied the effects of linear elastic deformation and lubricant viscosity with pressure and temperature for an elliptical bearing and solved 3-D equations for momentum, continuity and elasticity to obtain pressure in the lubricant flow-field and deformation in the bearing liner. Basri and Gethin [1990] have carried out a theoretical analysis of the thermal behaviour of orthogonally displaced, threelobe, and four-lobe bearing geometries. The thermal analysis illustrates the implication of the type selection with regards to the parameters of load-carrying ability, power loss, lubricant requirements, and operating temperatures. The comparisons presented by the authors, show that all profiles considered have inferior load-carrying ability and less extreme thermal effects when compared with the cylindrical geometry along with significantly larger lubricant supply requirements. Hussain et al. [1996] have predicted the temperature distribution in various non-circular journal bearings namely two-lobe, elliptical, and orthogonally displaced. The work reported by them is based on a twodimensional treatment following Mc Callion's approach in which the Reynolds and energy equations in oil film are decoupled by neglecting all pressure terms in the energy equation. $\mathrm{Ma}$ and Taylor [1996] experimentally investigated the thermal behaviour of a two-axialgroove circular bearing and an elliptical bearing, both $110 \mathrm{~mm}$ in diameter. Both bearings were tested at specific loads upto $4 \mathrm{MPa}$ and rotational frequencies up to $120 \mathrm{~Hz}$. The authors have measured the power losses \& flow rates directly, and the detailed temperature information was collected. The results presented by them show that the thermal effects are significant in both bearings. Banwait and Chandrawat [2000] have analyzed the effect of journal misalignment on the thermohydrodynamic performance characteristics of elliptical journal bearing and solved the generalized Reynolds equation for the oil-film pressure distribution. The energy and heat conduction equations are used by the authors for determining the oil-film, bush and journal temperature fields. This work has reported the important features observed in static performance characteristics of thermohydrodynamic analysis of misaligned elliptical bearing along with the isopressure curves, pressure profiles, isotherms and temperature profiles. Sehgal et al. [2000] have presented a comparative analysis of three types of hydrodynamic journal bearing configurations namely, circular, axial groove, and offset-halves. It has been reported by the authors that the offset bearing runs cooler than an equivalent circular bearing with axial grooves. A computer-aided design of hydrodynamic journal bearing is provided considering thermal effects by Singh and Majumdar [2005]. They have solved the Reynolds equation simultaneously along with the energy equation and heat conduction equations in bush and shaft to obtain the steady-state solution. A data bank is generated by the authors that consists of load, friction factor and flow rate for different L/D \& eccentricity ratios. Sharma and Pandey [2007] have carried out a thermohydrodynamic lubrication analysis of infinitely wide slider bearing assuming parabolic and Legendre polynomial temperature profile across the film thickness. It was observed that the temperature approximation across the film thickness by Legendre 
Polynomial yields more accurate results in comparison to Parabolic Profile approximation. However, the former is algebraically more complex to tackle in comparison to the later; the authors also observed that the film temperatures computed by Parabolic Profile approximation are lower in comparison to Legendre Polynomial approximation. Further, it has been concluded by them that the computational time taken in solution of coupled governing equation with both temperature profile approximation have only marginal difference. Mishra et al. [2007] have considered the non-circularity in bearing bore as elliptical and made a comparison with the circular case to analyse the effect of irregularity. It was reported that, with increasing non-circularity, the pressure gets reduced and temperature rise obtained is less. Chauhan et al. [2010] have presented a thermohydrodynamic study for the analysis of elliptical journal bearing with three different grade oils. The authors have made a comparative study of rise in oil-temperatures, thermal pressures, and load carrying capacity for three commercial grade oils. Rahmatabadi et al. [2010] have considered the non-circular bearing configurations: two, three and four-lobe lubricated with micropolar fluids. The authors have modified the Reynolds equation based on the theory of micropolar fluids and solved the same by using finite element methods. It has been observed by the authors that micropolar lubricants can produce significant enhancement in the static performance characteristics and the effects are more pronounced at larger coupling numbers.

\section{Numerical techniques for the thermal analysis of non-circular journal bearing}

In earlier works, the bearing performance parameters have been computed by solving the Reynolds equation only. Over the years, many researchers have proposed number of mathematical models. A more realistic thermohydrodynamic (THD) model for bearing analysis has been developed which treats the viscosity as a function of both the temperature and pressure. Moreover, it also considers the variation of temperature across the film thickness and through the bounding solids (housing and Journal). The thermohydrodynamic model also presents coupled solutions of governing equations by incorporating appropriate boundary conditions and considering the heat conduction across the bearing surfaces. Even the importance of THD studies in hydrodynamic bearings can be justified by looking at the large volumes of research papers that are being published by researchers using various models. The theoretical investigations have been carried out into the performance of hydrodynamic journal bearing by adopting various methods, which are classified in two categories as: First category is the methods which comprise a full numerical treatment of temperature variation across the lubrication film thickness in energy equation using Finite Difference Method (FDM) or Finite Element Method (FEM). Second one is the methods which incorporate polynomial approximation to evaluate the transverse temperature variation in the lubrication film thickness. Both approaches mentioned can be used for the analysis of hydrodynamic bearings and have certain merits. The first approach is relatively accurate at the expense of computational speed and time, whereas the second is relatively fast at the expense of accuracy. 
In present chapter, the thermal studies of non-circular journal bearings: offset-halves and elliptical have been presented using thermohydrodynamic approach.

\subsection{Film thickness equation}

The film thickness equations for offset-halves journal bearing (Fig. 1 (a)) are given as Sehgal et al. [2000]:

$$
\begin{gathered}
h=c_{m}\left[\left(\frac{1+\delta}{2 \delta}\right)+\left(\frac{1-\delta}{2 \delta}\right) \cos \theta-\varepsilon \sin (\phi-\theta)\right](0<\theta<180) \\
h=c_{m}\left[\left(\frac{1+\delta}{2 \delta}\right)-\left(\frac{1-\delta}{2 \delta}\right) \cos \theta-\varepsilon \sin (\phi-\theta)\right](180<\theta<360)
\end{gathered}
$$

In these equations, $h$ represents film thickness for circular journal bearing, $C$ represents radial clearance, $\varepsilon$ represents eccentricity ratio, and $\theta$ represents angle measured from the horizontal split axis in the direction of rotation. $C_{m}$ denotes minimum clearance when journal centre is coincident with geometric centre of the bearing, $\delta$ denotes offset factor $\left(C_{m} / C\right)$, and $\phi$ denotes attitude angle.

The film thickness equations for elliptical journal bearing (Fig. 1 (b)) are given as Hussain et al. [1996]:

$$
\begin{gathered}
h=c_{m}\left[1+E_{M}+\varepsilon_{1} \cos \left(\theta+\phi-\phi_{1}\right)\right], \text { for } 0<\theta<180 \\
h=c_{m}\left[1+E_{M}+\varepsilon_{2} \cos \left(\theta+\phi-\phi_{2}\right)\right], \text { for }(180<\theta<360)
\end{gathered}
$$

Different parameters used in eqns. (3) \& (4) are given as:

$$
\begin{gathered}
\varepsilon_{1}=\left(E_{M}^{2}+\varepsilon^{2}-2 E_{M} \varepsilon \cos \phi\right)^{\frac{1}{2}} ; \varepsilon_{2}=\left(E_{M}{ }^{2}+\varepsilon^{2}+2 E_{M} \varepsilon \cos \phi\right)^{\frac{1}{2}} \\
\phi_{1}=\pi-\tan ^{-1}\left(\frac{\varepsilon \sin \phi}{E_{M}-\varepsilon \cos \phi}\right) ; \phi_{2}=\tan ^{-1}\left(\frac{\varepsilon \sin \phi}{E_{M}+\varepsilon \cos \phi}\right) ; E_{M}=\left(\frac{C_{h}-C_{m}}{C_{m}}\right)
\end{gathered}
$$

In eqns. (3 and 4), $h$ represents film thickness for elliptical journal bearing, $E_{M}$ represents elliptical Ratio, $\varepsilon_{1}, \varepsilon_{2}$ represents eccentricity ratio from 0-180 Deg. (upper lobe) and 180-360 Deg. (lower lobe) respectively, $\phi_{1}, \phi_{2}$ represents attitude angles from 0-180 Deg. (upper lobe) and 180-360 Deg. (lower lobe) respectively and $C_{h}$ represents horizontal clearance for elliptical journal bearing. Film thickness represented by eqns. 1, 3 corresponds to upper lobe whereas eqns. 2, 4 represents film thickness for lower lobe of the. 


\subsection{Reynolds equation}

All the simplifying assumptions necessary for the derivation of the Reynolds equation are listed below Stachowiak and Batchelor [1993]:

1. Body forces are neglected i. e. there are no extra outside fields of forces acting on the fluids.

2. Pressure is constant through the film.

3. No slip at the boundaries as the velocity of the oil layer adjacent to the boundary is the same as that of the boundary.

4. Flow is laminar and viscous.

5. Lubricant behaves as a Newtonian fluid.

6. Inertia and body forces are negligible compared with the pressure and viscous terms.

7. Fluid density is constant. Usually valid for fluids, when there is not much thermal expansion.

8. There is no vertical flow across the film.

For steady-state and incompressible flow, the Reynolds equation is Hussain et al. [1996]:

$$
\frac{\partial}{\partial x}\left(\frac{h^{3}}{\mu} \frac{\partial p}{\partial x}\right)+\frac{\partial}{\partial z}\left(\frac{h^{3}}{\mu} \frac{\partial p}{\partial z}\right)=6 U \frac{\partial h}{\partial x}
$$

Here, $P$ represents film pressure, $\mu$ represents absolute viscosity of the lubricant, and $U$ represents velocity of journal.

This equation is set into finite differences by using central difference technique. The final form is reproduced here.

$$
\begin{gathered}
P(i, j)_{i s o}=A 1 P(i+1, j)_{i s o}+A 2 P(i-1, j)_{i s o}+A 3 P(i, j+1)_{i s o}+A 4 P(i, j-1)_{i s o}-A 5 \\
P(i, j)_{t h}=E 11 P(i+1, j)_{t h}+E 22 P(i-1, j)_{t h}+E 33 P(i, j+1)_{t h}+E 44 P(i, j-1)_{t h}-E 55 \\
\text { Where, } A 11=\left[\frac{h^{3}}{d \theta^{2}}+\frac{3 h^{2}}{2 d \theta} \frac{\partial h}{\partial \theta}\right] ; A 22=\left[\frac{h^{3}}{d \theta^{2}}-\frac{3 h^{2}}{2 d \theta} \frac{\partial h}{\partial \theta}\right] ; A 33=\left[\frac{r^{2} h^{3}}{d z^{2}}+\frac{3 r^{2} h^{2}}{2 d z} \frac{\partial h}{\partial z}\right] ; \\
A 44=\left[\frac{r^{2} h^{3}}{d z^{2}}-\frac{3 r^{2} h^{2}}{2 d z} \frac{\partial h}{\partial z}\right] ; A 55=\left[6 U r \mu \frac{\partial h}{\partial \theta}\right] ; A=\left[\frac{2 h^{3}}{d \theta^{2}}+\frac{2 r^{2} h^{2}}{d z^{2}}\right] ; \\
A 1=A 11 / A ; A 2=A 22 / A ; A 3=A 33 / A ; A 4=A 44 / A ; A 5=A 55 / A \\
A 6=\frac{h^{3}}{\mu} ; A 7=\frac{\partial A 6}{\partial \theta} ; A 8=\frac{\partial A 6}{\partial z} ; A 9=\frac{2 A 6}{d \theta^{2}}+\frac{2 r^{2} A 6}{d z^{2}} ; F=\frac{A 7}{2 d \theta} ; G=\frac{A 6}{d \theta^{2}} ; B=\frac{\partial h}{\partial \theta} ; \\
H=\frac{r^{2} A 8}{2 d z} ; H 1=\frac{r^{2} A 6}{d z^{2}} ; H 2=6 U r B ; E 11=\frac{F+G}{A 9} ; E 22=\frac{-F+G}{A 9} ;
\end{gathered}
$$




$$
E 33=\frac{H+H 1}{A 9} ; E 44=\frac{-H+H 1}{A 9} ; E 55=\frac{-H 2}{A 9}
$$

Equation (6) assumes viscosity as constant and gives isothermal pressures, whereas eqn. (7) assumes viscosity as a variable quantity and gives thermal pressures. The coefficients appearing in eqn. $(6 \& 7)$ are given in Appendix-I. The variation of viscosity with temperature and pressure has been simulated using the following viscosity relation Sharma and Pandey [2007]:

$$
\mu=\mu_{r e f} e^{\alpha P-\gamma\left(T-T_{0}\right)}
$$

In eqn. (8), $\mu_{r e f}$ represents absolute viscosity of the lubricant at oil inlet temperature, $\gamma$ represents temperature-viscosity coefficient of lubricant, $\alpha$ represents Barus viscositypressure index, $T$ represents lubricating film temperature, and $T_{o}$ represents oil inlet temperature.

\subsection{Energy Equation}

The energy equation for steady-state and incompressible flow is given as Sharma and Pandey [2007]:

$$
\rho C_{P}\left(u \frac{\partial T}{\partial x}+w \frac{\partial T}{\partial z}\right)=\frac{\partial}{\partial y}\left(K \frac{\partial T}{\partial y}\right)+\mu\left[\left(\frac{\partial u}{\partial y}\right)^{2}+\left(\frac{\partial w}{\partial y}\right)^{2}\right]
$$

Here, $C_{P}$ represents specific heat of the lubricating oil, $K$ represents thermal conductivity of the lubricating oil, and $u, w$ represents velocity components in X-and Z-directions. The term on the left hand side in eqn. (9) represents the energy transfer due to convection, and the first, second terms on right hand side of the eqn. (9) represents the energy transfer due to conduction and energy transfer due to dissipation respectively. In eqn. (9), x-axis represents the axis along the circumference of bearing, $y$-axis represents the axis along the oil film thickness and $z$-axis represents the axis across the width of bearing. The variation of temperature across the film thickness in equation (9) is approximated by parabolic temperature profile. It is pertinent to add here that the temperature computed by this approach have been reported to be on lower side in comparison to those obtained through Legendre polynomial temperature profile approximation by Sharma and Pandey [2006]. The temperature profile across the film thickness is represented by a second order polynomial as:

$$
T=a_{1}+a_{2} y+a_{3} y^{2}
$$

In order to evaluate the constants appearing in eqn. (10), the following boundary conditions are used:

$$
\text { At } y=0, T=T_{L}
$$




$$
\text { At } y=h, T=T_{U}
$$

and

$$
T_{m}=\frac{1}{h} \int_{0}^{h} T d y
$$

After algebraic manipulations, the equation (10) takes the following form:

$$
T=T_{L}-\left(4 T_{L}+2 T_{U}-6 T_{m}\right)\left(\frac{y}{h}\right)+\left(3 T_{L}+3 T_{U}-6 T_{m}\right)\left(\frac{y}{h}\right)^{2}
$$

Where, $T_{L}, T_{U}$ and $T_{m}$ represent temperatures of the lower bounding surface (journal), upper bounding surface (bearing), and mean temperature across the film respectively.

Final form of the energy equation is represented as:

$$
\begin{aligned}
& 6 T_{L}+6 T_{U}-12 T_{m}-\frac{\rho C_{P} h^{4}}{120 K \mu} \frac{\partial P}{\partial x}\left(\frac{\partial T_{L}}{\partial x}+\frac{\partial T_{U}}{\partial x}-12 \frac{\partial T_{m}}{\partial x}\right)-\frac{\rho C_{P} h^{4}}{120 K \mu} \frac{\partial P}{\partial z} \\
& \left(\frac{\partial T_{L}}{\partial z}+\frac{\partial T_{U}}{\partial z}-12 \frac{\partial T_{m}}{\partial z}\right)-\frac{\rho C_{P} h^{2}\left(u_{L}+u_{U}\right)}{2 K} \frac{\partial T_{m}}{\partial x}-\frac{\rho C_{P} h^{2}\left(u_{U}-u_{L}\right)}{12 K}\left(\frac{\partial T_{U}}{\partial x}-\frac{\partial T_{L}}{\partial x}\right) \\
& +\frac{h^{4}}{12 K \mu}\left[\left(\frac{\partial P}{\partial x}\right)^{2}+\left(\frac{\partial P}{\partial z}\right)^{2}\right]+\frac{\mu\left(u_{U}-u_{L}\right)^{2}}{K}=0
\end{aligned}
$$

\subsection{Heat conduction equation}

The temperature in bush is determined by using the Laplace equation within the bearing material as given below Hori [2006]:

$$
\frac{\partial^{2} T_{b}}{\partial x^{2}}+\frac{\partial^{2} T_{b}}{\partial y^{2}}+\frac{\partial^{2} T_{b}}{\partial z^{2}}=0
$$

In this equation, $r$ stands for bush radius, and $T_{b}$ stands for bush temperature. The equation (13) is then set into finite differences by using central difference technique. The final form is reproduced here.

$$
\begin{aligned}
& T_{b}(i, j, k)=E 1 T_{b}(i+1, j, k)+E 1 T_{b}(i-1, j, k)+E 2 T_{b}(i, j+1, k)+E 2 T_{b}(i, j-1, k)+ \\
& E 3 T_{b}(i, j, k+1)+E 3 T_{b}(i, j, k-1)
\end{aligned}
$$

Where, $E=\left[\frac{2}{r^{2} d \theta^{2}}+\frac{2}{d y^{2}}+\frac{2}{d z^{2}}\right] ; F 11=\frac{1}{r^{2} d \theta^{2}} ; F 22=\frac{1}{d z^{2}} ; F 33=\frac{1}{d y^{2}}$;

$$
E 1=F 11 / E ; E 2=F 22 / E ; E 3=F 33 / E
$$




\subsection{Computation procedure}

Coupled numerical solutions of Reynolds, energy and heat conduction equations are obtained for offset-halves and elliptical journal bearings. The temperature of upper and lower bounding surfaces have been assumed constant throughout and set equal to oil inlet temperature for first iteration. For subsequent iterations the temperatures at oil bush interface are computed using heat conduction equations and appropriate boundary conditions. The numerical procedure adopted for obtaining the thermohydrodynamic solution is discussed below.

a. Reynolds Equation

A suitable initial value of attitude angle is assumed and film thickness equations (1-4) are solved. Then equation (6) has been used to find isothermal pressures. The initial viscosity values are assumed to be equal to the inlet oil viscosity.

b. Energy equation

The solution for the determination of temperature begins with the known pressure distributions obtained by solution of Reynolds equation. Viscosity variation in the fluid film domain corresponding to computed temperatures and pressures is calculated using equation (8). With new value of viscosity, equation (7) has been solved for thermal pressure. These values of pressure and viscosity, are used to further solve energy equation (12). Mean temperatures obtained by solving equation (12) are substituted in equation (11) to find the temperature in the oil film. Now, this temperature is used to solve the equation (13) to obtain the temperature variation in the bush. The computation is continued till converged solutions for thermal pressure loop and temperature loop have been arrived. The load carrying capacity is obtained by applying the Simpson rule to the pressure distribution. In computation, wherever reverse flow arises in domain, upwind differencing has been resorted to. Power losses have been evaluated by the determination of shear forces, and then employing the Simpson rule.

The boundary conditions used in the solution of governing equations are:

$\begin{array}{llllr}P=0 & \text { at } & x=0 & \text { and } & x=l \\ u=u_{L} & \text { at } & y=0 & \text { and } & 0 \leq x \leq l \\ u=0 & \text { at } & y=h & \text { and } & 0 \leq x \leq l \\ T=T_{0} & \text { at } & x=0 & \text { and } & 0 \leq x \leq h \\ T=T_{L} & \text { at } & y=0 & \text { and } & 0 \leq x \leq l \\ T=T_{U} & \text { at } & y=h & \text { and } & 0 \leq x \leq l\end{array}$




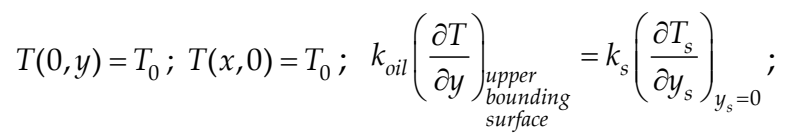

$$
\begin{aligned}
& -k_{s}\left(\frac{\partial T_{s}}{\partial y_{s}}\right)_{y_{s}=t}=h_{c}\left(T_{s}\left(x_{s}, t\right)-T_{a}\right) ; \quad-k_{s}\left(\frac{\partial T_{s}}{\partial x_{s}}\right)_{x_{s}=0}=h_{c}\left(T_{s}\left(0, y_{s}\right)-T_{a}\right) \\
& -k_{s}\left(\frac{\partial T_{s}}{\partial x_{s}}\right)_{x_{s}=l}=h_{c}\left(T_{s}\left(l, y_{s}\right)-T_{a}\right) ; \quad k_{s}\left(\frac{\partial T_{s}}{\partial z_{s}}\right)_{z_{s}=0}=h_{c}\left(T_{s}\left(x_{s}, y_{s}, 0\right)-T_{a}\right) ; \\
& -k_{s}\left(\frac{\partial T_{s}}{\partial z_{s}}\right)_{z_{s}=b}=h_{c}\left(T_{s}\left(x_{s}, y_{s}, b\right)-T_{a}\right)
\end{aligned}
$$

Where, $K_{s}$ denotes thermal conductivity of bearing, $h_{c}$ denotes convection heat transfer coefficient of bush, $l$ denotes length of the bearing, $s$ denotes bearing surface, $t$ denotes thickness of bearing, $b$ denotes width of bearing, and $T_{a}$ ambient temperature.

The solution of governing equations has been achieved by satisfying the convergence criterion given below:

For pressure:

$$
\frac{\mid\left(\sum P_{i, j}\right)_{n-1}-\left(\sum P_{i, j}\right)_{n} \mathrm{|}}{\left|\left(\sum P_{i, j}\right)_{n}\right|} \leq 0.0001
$$

For temperature:

$$
\frac{\left|\left(\sum T_{i, j}\right)_{n-1}-\left(\sum T_{i, j}\right)_{n}\right|}{\left|\left(\sum T_{i, j}\right)_{n}\right|} \leq 0.0001
$$

Where, $\mathrm{n}$ represents number of iterations.

Here, the authors have made an attempt to present some performance parameters of offsethalves and elliptical journal bearing which have been evaluated using computer program developed by them based on method discussed in the previous articles of the chapter. Input parameters of offset-halves and elliptical journal bearing, and the properties of the grade oils and material used to manufacture the bearings are given in Tables 1, 2, and 3 . The study has been carried at oil inlet temperature of $33^{\circ} \mathrm{C}$ (which has been used as reference inlet temperature of the oil by most of the researchers) for the eccentricity ratios equal to 0.6 and speeds ranging from $3000 \mathrm{rpm}-4000 \mathrm{rpm}$. 


\begin{tabular}{|l|c|c|c|}
\hline \multicolumn{1}{|c|}{ Parameter } & Dimension & Tolerance & Roughness \\
\hline Outer diameter of the bearing, OD & $85 \mathrm{~mm}$ & $\pm 0.2 \mathrm{~mm}$ & $10 \mu \mathrm{m}$ \\
\hline Inner diameter of the bearing, ID & $65 \mathrm{~mm}$ & $\pm 0.2 \mathrm{~mm}$ & $10 \mu \mathrm{m}$ \\
\hline Length, L & $65 \mathrm{~mm}$ & $\pm 0.2 \mathrm{~mm}$ & $10 \mu \mathrm{m}$ \\
\hline Radial Clearance, C & $500 \mu \mathrm{m}$ & $\pm 50 \mu \mathrm{m}$ & \\
\hline Minimum Clearance, Cm & $200 \mu \mathrm{m}$ & $\pm 50 \mu \mathrm{m}$ & \\
\hline Oil hole & $6.35 \mathrm{~mm}$ & $\pm 0.15 \mathrm{~mm}$ & \\
\hline Relative sensor position & $45^{\mathbf{o}}$ & $\pm 1^{\mathrm{o}}$ & \\
\hline
\end{tabular}

Table 1. Input parameters used to study the performance characteristics of offset-halves journal bearing [Chauhan: 2011]

\begin{tabular}{|l|c|c|c|}
\hline \multicolumn{1}{|c|}{ Parameter } & Dimension & Tolerance & Roughness \\
\hline Outer diameter of the bearing, OD & $85 \mathrm{~mm}$ & $\pm 0.2 \mathrm{~mm}$ & $10 \mu \mathrm{m}$ \\
\hline Maximum inner diameter of the bearing, DImax & $65.4 \mathrm{~mm}$ & $\pm 0.2 \mathrm{~mm}$ & $10 \mu \mathrm{m}$ \\
\hline Minimum inner diameter of the bearing, DImin & $65.2 \mathrm{~mm}$ & $\pm 0.2 \mathrm{~mm}$ & $10 \mu \mathrm{m}$ \\
\hline Length, L & $65 \mathrm{~mm}$ & $\pm 0.2 \mathrm{~mm}$ & $10 \mu \mathrm{m}$ \\
\hline Radial Clearance, C & $300 \mu \mathrm{m}$ & $\pm 50 \mu \mathrm{m}$ & \\
\hline Minimum Clearance, Cm & $200 \mu \mathrm{m}$ & $\pm 50 \mu \mathrm{m}$ & \\
\hline Oil hole & $6.35 \mathrm{~mm}$ & $\pm 0.15 \mathrm{~mm}$ & \\
\hline Relative sensor position & $45^{\circ}$ & $\pm 1^{\circ}$ & \\
\hline
\end{tabular}

Table 2. Input parameters used to study the performance characteristics of elliptical journal bearing [Chauhan: 2011]

\begin{tabular}{|c|c|c|c|}
\hline & $\begin{array}{c}\text { Oil 1 } \\
\text { (Hydrol 68) } \\
\end{array}$ & $\begin{array}{c}\text { Oil 2 } \\
(\text { Mak 2T) }\end{array}$ & $\begin{array}{c}\text { Oil 3 } \\
\text { (Mak Multigrade) } \\
\end{array}$ \\
\hline Viscosity, $\mu$ (at $T_{o}=33{ }^{0} \mathrm{C}$ ) & 0.075 Pas & 0.065 Pas & $0.200 \mathrm{Pas}$ \\
\hline Viscosity, $\mu$ (at $T_{o}=100{ }^{0} \mathrm{C}$ ) & 0.00771 Pas & 0.004861 Pas & 0.01239 Pas \\
\hline Density, $\rho$ & $880 \mathrm{Kg} / \mathrm{m}^{3}$ & $868 \mathrm{Kg} / \mathrm{m}^{3}$ & $885 \mathrm{Kg} / \mathrm{m}^{3}$ \\
\hline Thermal conductivity ${ }^{* *}, K_{\text {oil }}$ & $0.126 \mathrm{~W} / \mathrm{m}^{0} \mathrm{C}$ & $0.126 \mathrm{~W} / \mathrm{m}{ }^{0} \mathrm{C}$ & $0.126 \mathrm{~W} / \mathrm{m}{ }^{0} \mathrm{C}$ \\
\hline Viscosity index ${ }^{*}$ & 98 & 135 & 110 \\
\hline Flash point ${ }^{*},{ }^{0} \mathrm{C}$ & 230 & 94 & 200 \\
\hline Pour point ${ }^{*},{ }^{0} \mathrm{C}$ & -9 & -24 & -21 \\
\hline Barus viscosity-pressure index ${ }^{* *}, \alpha$ & \multicolumn{3}{|c|}{ 2.3e- $8 P a^{-1}$} \\
\hline Temperature viscosity- coefficient ${ }^{* *}, \gamma$ & \multicolumn{3}{|c|}{$0.034 K^{-1}$} \\
\hline Thermal conductivity of bush ${ }^{* *}, K_{b u s h}$ & \multicolumn{3}{|c|}{$0.22 \mathrm{~W} / \mathrm{m}$ Deg.C } \\
\hline Coefficient of thermal expansion of bush, $h_{b u s h}$ & \multicolumn{3}{|c|}{$75 e-6 K^{-1}$} \\
\hline
\end{tabular}

Table 3. Properties of the bush material (Methyl Methacrylite) and grade oils under study [Chauhan et al. 2011] 
Figures 5, and 6, show the variation of oil film temperature in the central plane of the bearing for eccentricity ratio, $\varepsilon=0.6$ at oil inlet temperature of $33{ }^{0} \mathrm{C}$ for all the three grade oils under study at speeds $4000 \mathrm{rpm}$ for offset-halves and elliptical journal bearing respectively. It has been observed that oil film temperature rise is very high in lower lobe in comparison to oil film temperature rise in upper lobe for offset-halves, and the oil film temperature rise is though high in lower lobe but it is comparable with the rise in upper lobe of the elliptical journal bearing. A high temperature rise in Oil 3 compared to the other grade oils has been observed which may be because of its high viscosity value. Similarly, figures 7 and 8 , show the variation of thermal pressure in the central plane of the bearing for eccentricity ratio, $\varepsilon=0.6$ at oil inlet temperature of $33{ }^{\circ} \mathrm{C}$ for all the three grade oils under study at speeds $4000 \mathrm{rpm}$ for offset-halves and elliptical journal bearing respectively. It has been observed that thermal pressure rise is very high in lower lobe in comparison to thermal pressure rise in upper lobe for both offset-halves and elliptical journal bearing.

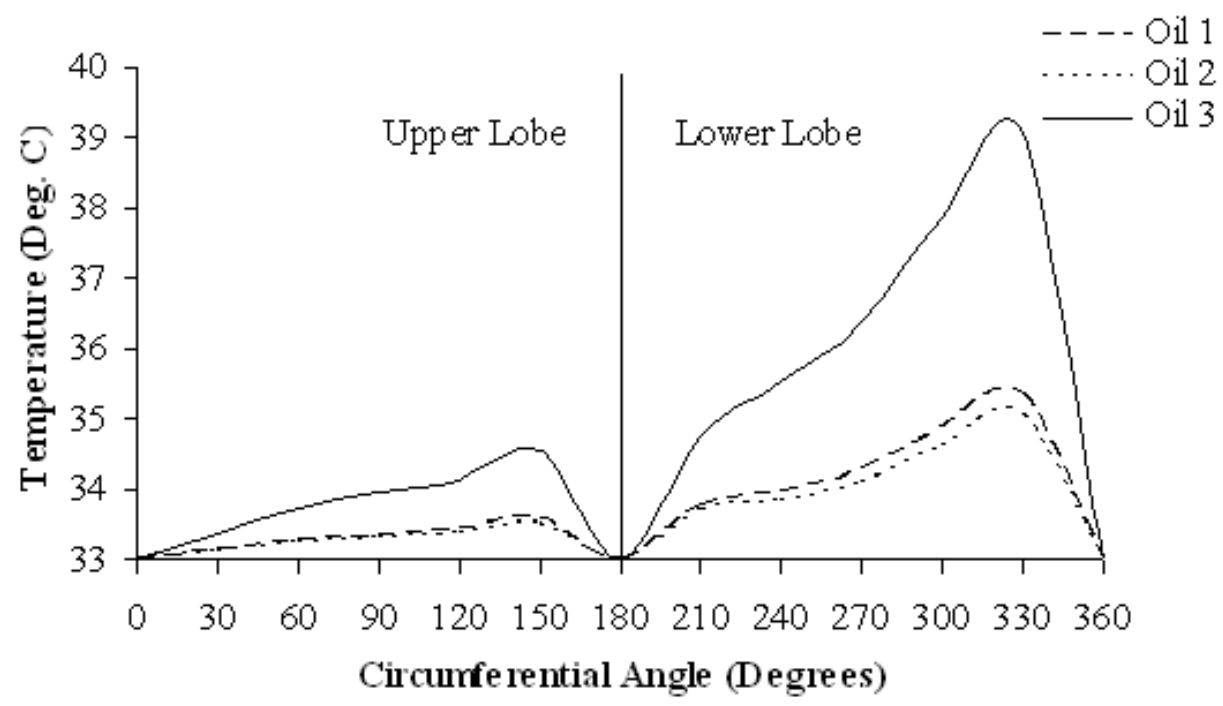

Figure 5. Variation of oil film temperatures in the central plane of the offset-halves bearing for different grade oils at $4000 \mathrm{rpm}$, oil inlet temperature $=33{ }^{\circ} \mathrm{C}$ and eccentricity ratio $=0.6$ 


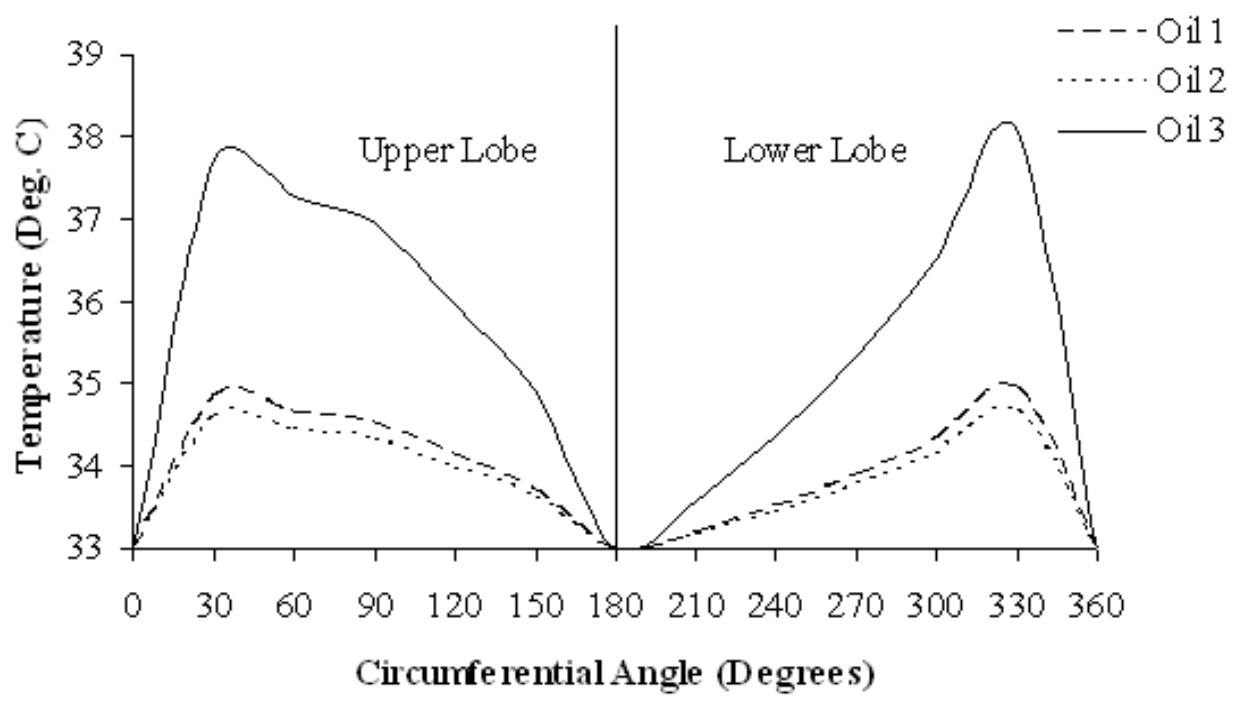

Figure 6. Variation of oil film temperatures in the central plane of the elliptical bearing for different grade oils at $4000 \mathrm{rpm}$, oil inlet temperature $=33^{\circ} \mathrm{C}$ and eccentricity ratio $=0.6$

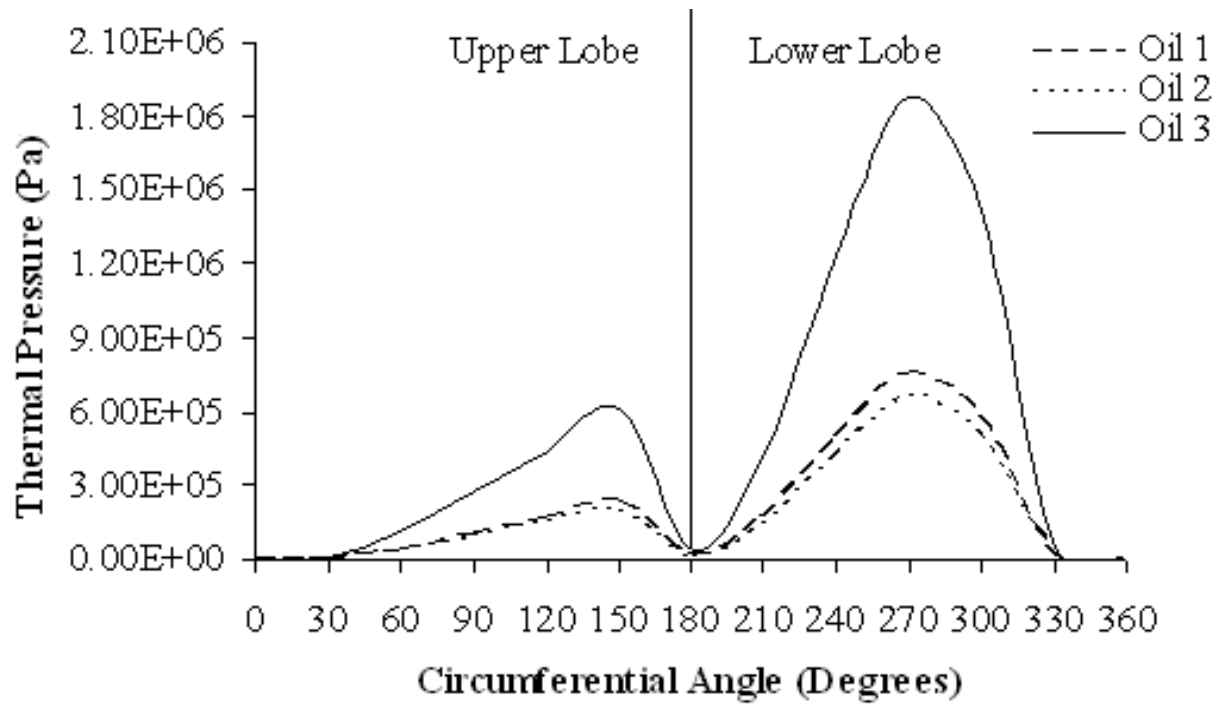

Figure 7. Variation of thermal pressure in the central plane of the offset-halves bearing for different grade oils at $4000 \mathrm{rpm}$, oil inlet temperature $=33^{\circ} \mathrm{C}$ and eccentricity ratio $=0.6$ 


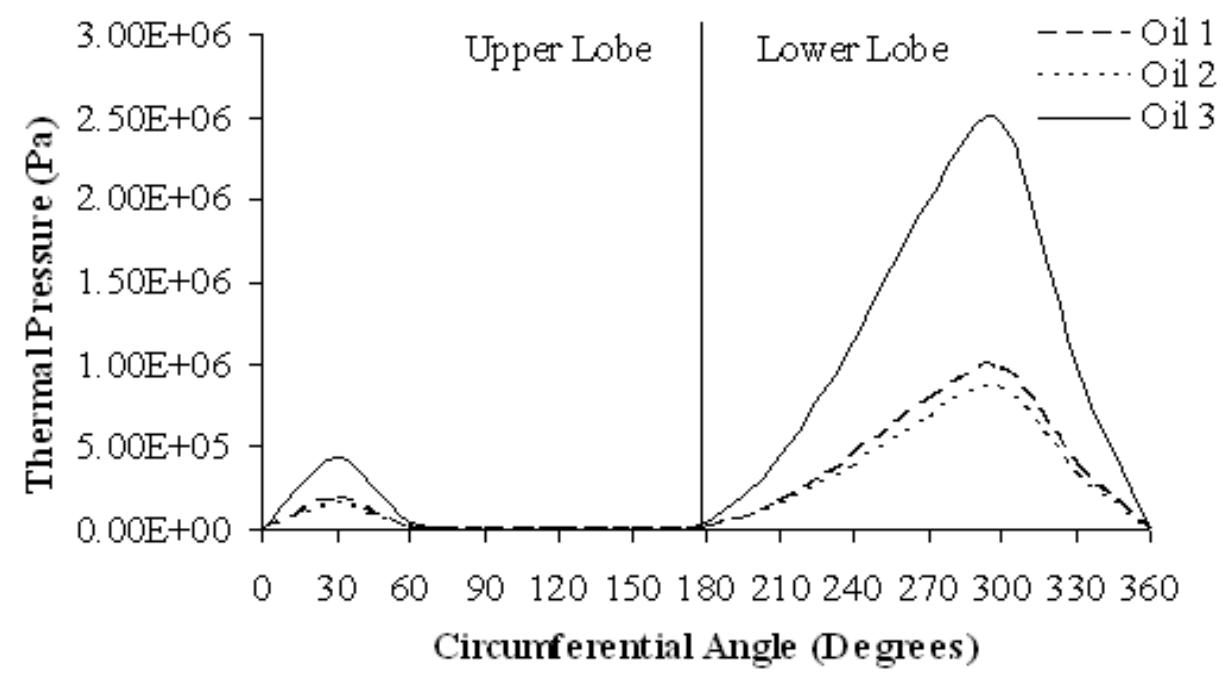

Figure 8. Variation of thermal pressure in the central plane of the elliptical bearing for different grade oils at $4000 \mathrm{rpm}$, oil inlet temperature $=33{ }^{\circ} \mathrm{C}$ and eccentricity ratio $=0.6$

The comparative study of performance characteristics like oil film temperature, thermal pressure, load capacity, and power loss for the bearing configurations under study has also been presented in figures 9, 10, 11, and 12. Fig. 9 shows, that the oil film temperature rise is on much higher side for upper lobe of elliptical journal bearing when compared to the oil film temperature rise of same lobe of the offset-halves journal bearing, whereas the oil film temperature in lower lobe of offset-halves journal bearing is little higher the oil film temperature rise in lower lobe of elliptical journal bearing. Hence, the overall oil film temperature rise and thermal pressure has been observed high for elliptical journal bearing. The load capacity and power losses have been found on higher side for Oil 3 and on lower side for Oil 1. The trend remains same for both the journal bearings. The load capacity and power loss has also been observed high for elliptical journal bearing when compared with offset-halves journal bearing. It can be concluded from the above discussion that the lubricating oil with higher viscosity value results in high oil film temperature rise, high thermal pressure, high load capacity and also high power loss value, whereas the lubricating oil with low viscous value results in low oil film temperature rise, low thermal pressure, little low load capacity and power loss value. 


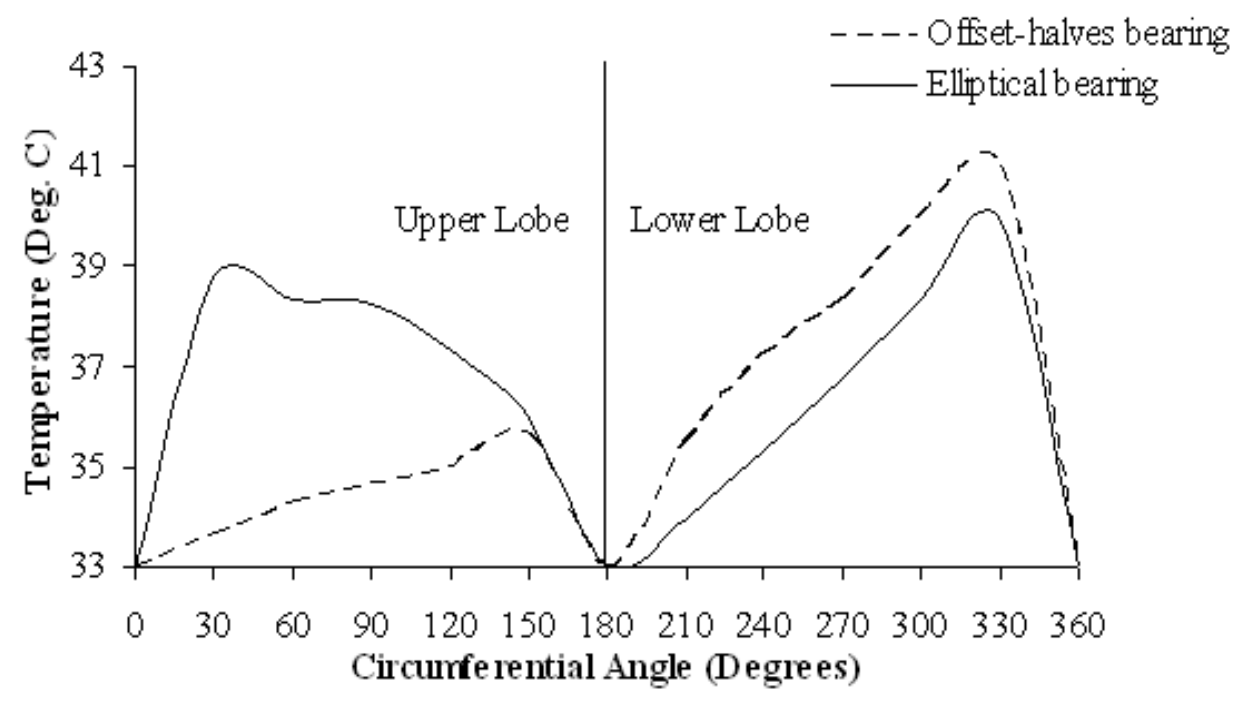

Figure 9. Variation of oil film temperature in the central plane with circumferential angle for Oil 1 at eccentricity ratio $=0.6$ and speed $=3000 \mathrm{rpm}$ for offset-halves and elliptical profile bearings $(\mathrm{d}=0.1 \mathrm{~m}$, $1 / \mathrm{d}=1, C=200 \mu m, C_{m}=120 \mu m, T_{o}=33^{0} \mathrm{C}$ )

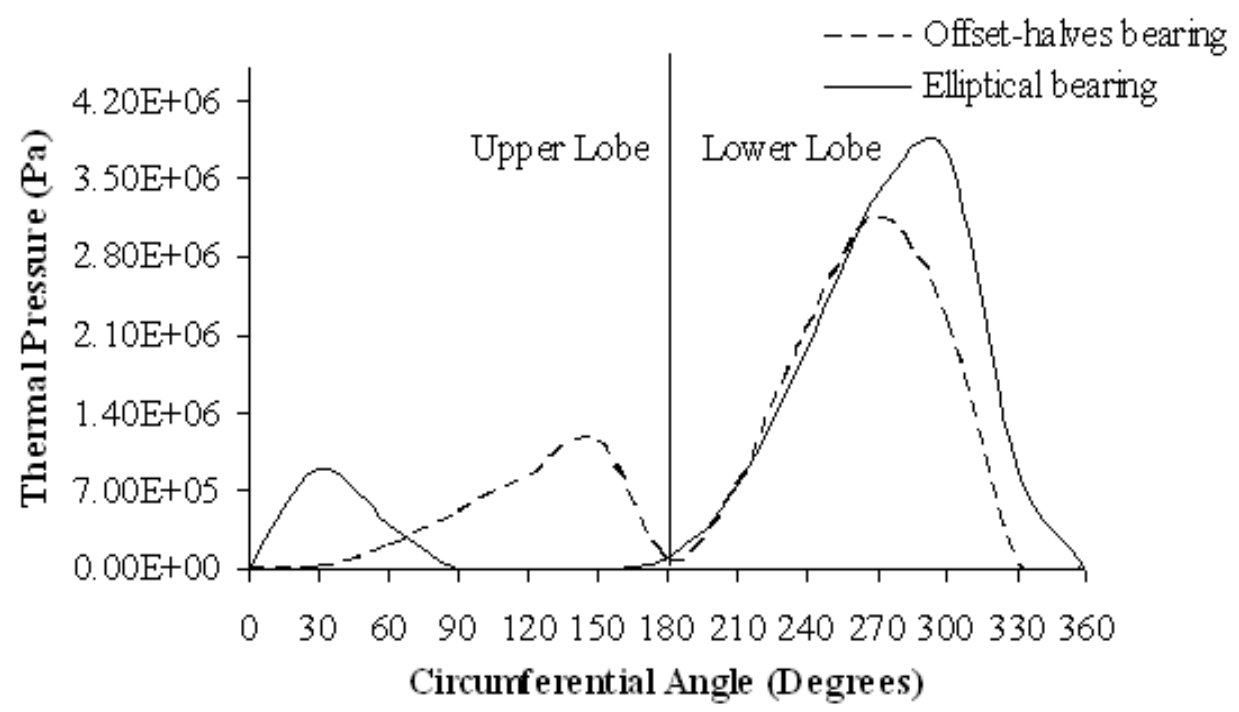

Figure 10. Variation of thermal pressure in the central plane with circumferential angle for Oil 1 at eccentricity ratio $=0.6$ and speed $=3000 \mathrm{rpm}$ for offset-halves and elliptical profile bearings $(\mathrm{d}=0.1 \mathrm{~m}$, $1 / \mathrm{d}=1, C=200 \mu m, C_{m}=120 \mu m, T_{o}=33{ }^{\circ} \mathrm{C}$ ) 


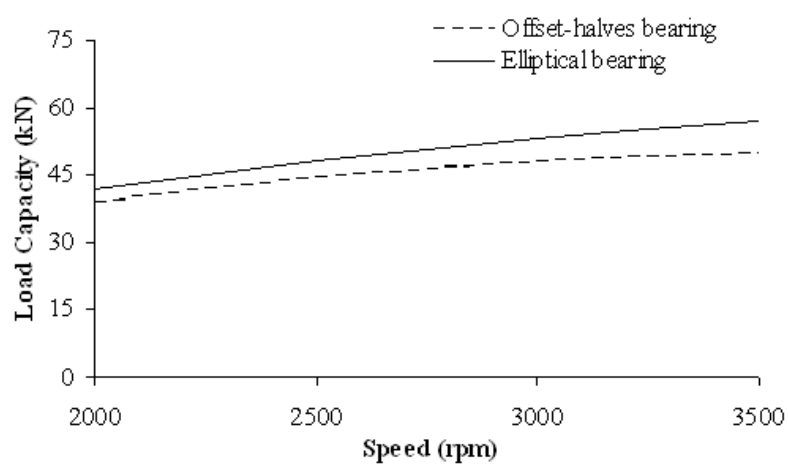

Figure 11. Variation of load capacity with speed for Oil 3 at eccentricity ratio $=0.7$ and speed $=3000 \mathrm{rpm}$ for offset-halves and elliptical profile bearings $\left(\mathrm{d}=0.1 \mathrm{~m}, \mathrm{l} / \mathrm{d}=1, C=200 \mu \mathrm{m}, C_{m}=120 \mu \mathrm{m}, T_{o}=33{ }^{0} \mathrm{C}\right.$ )

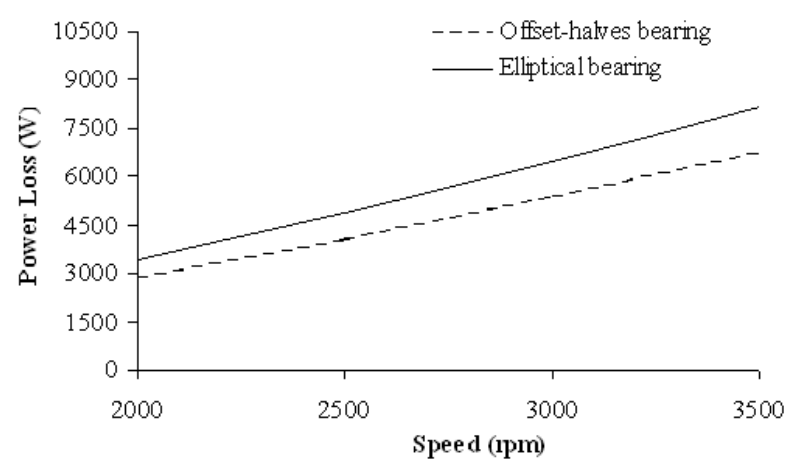

Figure 12. Variation of power loss with speed for Oil 3 at eccentricity ratio $=0.7$ and speed $=3000 \mathrm{rpm}$ for offset-halves and elliptical profile bearings $\left(\mathrm{d}=0.1 \mathrm{~m}, \mathrm{l} / \mathrm{d}=1, \mathrm{C}=200 \mu \mathrm{m}, \mathrm{C}_{m}=120 \mu \mathrm{m}, \mathrm{T}_{\mathrm{o}}=33{ }^{0} \mathrm{C}\right.$ )

\section{Conclusion}

This chapter deals with the thermal studies related to offset-halves and elliptical journal bearings. For each bearing configuration, the use of grade Oil 2 gives, the minimum temperature rise, and power losses which implies that the oil with low viscosity should be preferred as compared to high viscosity oil from thermal point of view and temperature rise is low for offset-halves bearing. An attempt has been made to compare the performance of two bearing configurations namely: offset-halves and elliptical journal bearings of same geometrical size by using three common commercial grade oils under similar operating conditions. Further, load carrying capacity of elliptical journal bearing has been found high in comparison to offset-halves journal bearing for same operating conditions. Among the two bearing configurations power losses are found to be minimum in case of offset-halves journal bearing. The chapter presents different performance parameters like oil film temperature, thermal pressures, load carrying capacity, and power losses which will help the designer to design this type of non-circular journal bearings as well as analyze their 
performance. The presently available design data/handbooks do not provide any direct analytical methods for the design and analysis of these non-circular journal bearings. However, the present methodology to a large extent has succeeded in standardizing the equations for design and analysis of these bearings.

\section{Author details}

Amit Chauhan

University Institute of Engineering and Technology, Sector-25,

Panjab University, Chandigarh, India

Rakesh Sehgal

Department of Mechanical Engineering, NIT Hamirpur (HP), India

\section{References}

[1] Banwait SS., and Chandrawat HN., "Effect of misalignment on thermohydrodynamic analysis of elliptical journal bearings", IE (I) J 2000; 81: 93-101.

[2] Basri S., and Gethin DT., "A comparative study of the thermal behaviour of profile bore bearings", Tribology International, 1990; 23: 265-276.

[3] Booker JF., And Govindachar S., "Stability of offset journal bearing systems", Proc. of IMechE 1984; C283/84: 269-275.

[4] Chandra M., Malik M., and Sinhasan R., “Comparative study of four gas-lubricated noncircular journal bearing configurations", Tribology International, 1983; 16: 103-108.

[5] Chauhan A., "Experimental and theoretical investigations of the thermal behaviour of some non-circular journal bearing profiles", Ph. D Thesis, NIT Hamirpur, 2011.

[6] Chauhan A., and Sehgal R., "An experimentation investigation of the variation of oil temperatures in offset-halves journal bearing profile using different oils", Indian Journal of Tribology, 2008; 2: 27-41.

[7] Chauhan A., Sehgal R., and Sharma RK., "Thermohydrodynamic analysis of elliptical journal bearing with different grade oils", Tribology International, 2010; 43: 1970-1977.

[8] Chauhan A., Sehgal R. and Sharma RK., "Investigations on the Thermal Effects in NonCircular Journal Bearings", Tribology International, 2011; 44; 1765-1773.

[9] Crosby WA., "Thermal considerations in the solution of finite journal bearings", Wear 1980; 64: 15-32.

[10] Fuller DD., "Theory and practice of lubrication for engineers", John Wiley and Sons, New York, 1956.

[11] Hori Y., "Hydrodynamic lubrication”, Springer-Verlag Tokyo, 2006.

[12] Hussain A., Mistry K., Biswas S., and Athre K., “Thermal analysis of Non-circular bearings", Trans ASME 1996; 118: 246-254.

[13] Ma MT. and Taylor M., "An experimental investigation of thermal effects in circular and elliptical plain journal bearings. Tribology International, 1996; 29(1): 19-26. 
[14] Mehta NP., and Singh A., "Stability analysis of Finite offset-halves pressure dam bearing", Trans ASME 1986; 108: 270-274.

[15] Mishra PC., Pandey RK., and Athre K., “Temperature profile of an elliptic bore journal bearing", Tribology International, 2007; 40(3): 453-458.

[16] Petrov NP., "Friction in machines and the effect of lubrication", Inzh. Zh. St. Peterburgo, 1883; 1: 71-140.

[17] Pinkus O., and Lynn, Mass., “Analysis of elliptical bearings”, Trans ASME 1956; 55LUB-22: 965-973.

[18] Rahmatabadi AD., Nekoeimehr M., and Rashidi R., "Micropolar lubricant effect on the performance of non-circular lobed bearings", Tribology International, 2010; 43: 404-413.

[19] Read LJ., and Flack RD., "Temperature, pressure and film thickness measurements for an offset half bearing", Wear 1987; 117(2): 197-210.

[20] Sehgal R., Swamy KNS., Athre K., and Biswas S., "A comparative study of the thermal behaviour of circular and non-circular journal bearings", Lub Sci 2000; 12(4): 329-344.

[21] Sharma RK., and Pandey RK., "An investigation into the validity of the temperature profile approximations across the film thickness in THD analysis of infinitely wide slider bearing", Tribol Onl 2006; 1: 19-24.

[22] Sharma RK., and Pandey RK., "Effects of the temperature profile approximations across the film thickness in Thermohydrodynamic analysis of Lubricating films", Ind J Tribol 2007; 2(1): 27-37.

[23] Singh A., and Gupta BK., "Stability limits of elliptical journal bearings supporting flexible rotors", Wear 1982; 77(2): 159-170.

[24] Singh A., and Gupta BK., "Stability analysis of orthogonally displaced bearings", Wear 1984; 97: 83-92.

[25] Singh DS., and Majumdar BC., "Computer-added design of hydrodynamic journal bearings considering thermal effects", Proc Inst Mech Eng, Part J: J Eng Tribol 2005; 219 : 133-143.

[26] Singh DV., Sinhasan R., and Prabhakaran Nair K., “Elastothermohydrodynamic effects in Elliptical bearings", Tribology International, 1989; 22(1): 43-49.

[27] Singh DV., Sinhasan R., and Kumar A., "A variational solution of two lobe bearings", Mechanism and Machine Theory, 1977; 12: 323-330.

[28] Stachowiak GW., and Batchelor AW., "Engineering tribology", Elsevier Science Publishers B. V., Netherlands, 1993: 123-131.

[29] Tayal SP., Sinhasan R., and Singh DV., "Finite element analysis of elliptical bearings lubricated by a non-Newtonian fluid", Wear 1982; 80: 71-81.

[30] Tower B., "First report on friction experiments", Proceedings of IMechE, 1883: 632-659.

[31] Wilcock DF., “Orthogonally displaced bearings-I”, ASLE Transactions, 1961; 4: 117-123.

[W1] www.roymech.co.uk/images3/lub_2.gif

[W2] www.reliabilitydirect.com/appnotes/jb.html 